\title{
Biobanking of fresh frozen tissue: RNA is stable in nonfixed surgical specimens
}

\author{
Patrick Micke ${ }^{1,3}$, Mitsuhiro Ohshima², Simin Tahmasebpoor ${ }^{3}$, Zhi-Ping Ren ${ }^{3}$, \\ Arne Östman ${ }^{1}$, Fredrik Pontén ${ }^{3}$ and Johan Botling ${ }^{3}$ \\ ${ }^{1}$ Cancer Center Karolinska, Department of Pathology-Oncology, Karolinska Institute, Stockholm, Sweden; \\ ${ }^{2}$ Department of Biochemistry, Nihon University School of Dentistry, Tokyo, Japan and ${ }^{3}$ Department of \\ Genetics and Pathology, Uppsala University, Uppsala, Sweden
}

\begin{abstract}
Molecular tools for tissue profiling, such as expression microarrays and real-time PCR, generally require collection of fresh frozen tissues as sources of high-quality RNA. The fragile nature of RNA prompted us to examine the effects of storage time and transport conditions with regard to RNA integrity and gene expression in nonfixed surgical human specimens. At surgery, fresh normal tonsil and colon tissue was cut into pieces and snap frozen. Additional fresh tissue pieces were (i) left at room temperature, (ii) kept on ice, (iii) in normal saline or (iv) in a commercial RNA-stabilizing buffer (RNAlater) and snap frozen after $0.5,1,3,6$ and $16 \mathrm{~h}$. Structural RNA integrity was analysed by microchip electrophoresis. Surprisingly, RNA remained stable in both tissue types under all conditions tested for up to $6-16 \mathrm{~h}$. Gene expression by real-time PCR of cfos, HIF1 $\alpha$, BcI2, PCNA, TGF $\beta 1$ and SMAD7 was analysed at different storage time points in tonsil tissue. Expression levels were essentially stable when samples were kept on ice, while marked regulation of single genes was observed during storage at room temperature, in normal saline and in RNAlater. Furthermore, we analysed selected tissue types from the local biobank representing $47 \mathrm{normal}$ and malignant tissues transported on ice for up to $2-3 \mathrm{~h}$ before biobanking. RNA prepared from $\mathbf{4 5}$ of the $\mathbf{4 7}$ samples exhibited distinct ribosomal peaks indicating intact RNA. This study shows that RNA degradation is a minor problem during handling of fresh human tissue before biobanking. Our data indicate that nonfixed tissue specimens may be transported on ice for hours without any major influence on RNA quality and expression of the selected genes. However, further studies are warranted to clarify the impact of transport logistics on global gene expression.
\end{abstract}

Laboratory Investigation (2006) 86, 202-211. doi:10.1038/labinvest.3700372; published online 9 January 2006

Keywords: biobank; RNA quality; Bioanalyzer; gene expression; fixative; frozen tissue

Archival human samples at pathology departments are usually formalin-fixed and stored as paraffin-embedded tissue blocks. However, as formalin fixation results in fragmentation of RNA, these archives are difficult to exploit using recently developed molecular tools that allow a comprehensive analysis of gene expression patterns. ${ }^{1-3}$ This has increased the efforts in recent years to establish biobanks of nonfixed frozen tissue. Together with attached relevant clinical information, these biobanks can provide researchers a reliable, organised source of human tissues for RNA-based analysis. Indeed, expression profiling of tumour tissues has revealed novel insights into pathogenetic mechanisms, and new disease classification schemes have incorporated diagnostic and

Correspondence: Dr J Botling, MD, PhD, Department of Genetics and Pathology, Rudbeck Laboratory, Uppsala University, SE 751 85 Uppsala, Sweden.

E-mail: Johan.Botling@genpat.uu.se

Received 9 May 2005; revised and accepted 14 October 2005; published online 9 January 2006 prognostic information from these studies. ${ }^{4-7}$ Therefore, RNA degradation is an important factor in biobank logistics.

The issue of RNA stability has been studied mostly with respect to various fixatives. ${ }^{8-14}$ However, studies are scarce concerning the handling of nonfixed tissue between surgery and subsequent freezing and storage at pathology departments. ${ }^{15}$ Immediate freezing of tissue specimens after surgery and further storage at $-80^{\circ} \mathrm{C}$ generally serve as the standard procedure for the procurement of surgical specimens. ${ }^{16-18}$ A longer noncontrolled time ex vivo before freezing is believed to have significant effects on RNA integrity and mRNA expression levels and could consequently influence results in gene expression studies. This is a considerable challenge for frozen tissue biobanks and has led to laborious and expensive logistics in many projects involving biobank personnel at the surgery departments and/ or use of expensive transportation media. However, it is not known if a longer transport time in a nonfixed state will disqualify a tissue sample from later RNA analysis. 
The aim of our study was to set up a systematic analysis that would reflect alternative routines for handling of nonfixed tissues, including different transport conditions and variable transportation times. The influence of these different conditions on RNA integrity and the relative mRNA expression levels of a selected set of genes were investigated. To evaluate the relevance of these experimental findings, we also tested RNA integrity in a number of different tissues collected routinely over the last years in the fresh frozen tissue biobank at our pathology department. The samples were chosen to represent benign and malignant tissue from different organs procured after different surgical procedures.

\section{Methods}

\section{Human Tissue Samples}

All tissue samples were collected and used in accordance with the ethical rules of the Department of Pathology, Uppsala University Hospital, and in agreement with the Swedish biobank legislation.

Fresh human tonsil tissue and fresh normal colon tissue was obtained directly after surgical resection at the operation theatre. The tissue was cut in cubes and four pieces of each tissue type were put in cryomolds and covered with cryogel (OCT, Histolab, Göteborg, Sweden), frozen in isopenthane/dry ice $\left(-120^{\circ} \mathrm{C}\right)$, and then transferred to a low-temperature freezer $\left(-80^{\circ} \mathrm{C}\right)$. These samples served as references (time point $0 \mathrm{~h}$ ). The remaining tissue cubes were transferred to four different jars and were then kept on ice $\left(0^{\circ} \mathrm{C}\right)$, at room temperature (RT, $+22^{\circ} \mathrm{C}$ ), immersed in cold $0.9 \%$ sodium chloride (only tonsil tissue), or immersed in cold RNAlater solution $\left(+4^{\circ} \mathrm{C}\right)$ (Ambion, Austin, USA). After 0.5, 1, 3, 6 and $16 \mathrm{~h}$, two tissue pieces were removed from each condition, frozen as above and transferred to $-80^{\circ} \mathrm{C}$ until RNA extraction.

The Fresh Tissue Biobank at the Department of Pathology, Uppsala University Hospital, collects fresh frozen tissue after routine surgery at the Hospitals of Uppsala County Community Council. The surgical specimens are wrapped fresh in a surgical cloth at the operation theatre and kept on ice $\left(0^{\circ} \mathrm{C}\right)$ during transport. Transport times usually vary between $15 \mathrm{~min}$ and $2-3 \mathrm{~h}$. At the Department of Pathology, the specimens are handled by a pathologist who cuts out tissue fractions for the biobank prior to fixation and further processing. Material is selected both from the lesion and the surrounding normal tissue, frozen as above, and transfered to $-80^{\circ} \mathrm{C}$.

\section{Cryosections for Light Microscopy}

Cryosections of tissues were made with a cryostat equipped with the CryoJane ${ }^{\mathbb{R}}$ Tape-Transfer system (CryoJane, Instrumedics Inc., Hackensack, USA).
The frozen tissue was cut in $4 \mu \mathrm{m}$-thick sections that were transferred on tape to an adhesive glass microscope slide (CryoJane). With a flash of ultraviolet light, the sections were permanently bonded to the glass. After fixation in glutaraldehyde, the sections were stained with hematoxylin-eosin according to standard procedures and evaluated microscopically.

\section{RNA Extraction}

Tissue samples were cut in $20 \mu$ m-thick sections with a cryostat. Three sections from each condition were directly immersed in either in $300 \mu \mathrm{l}$ Trizol (Invitrogen, Stockholm, Sweden) or $500 \mu \mathrm{l}$ extraction buffer (MicroRNA extraction-kit, Qiagen, Stockholm, Sweden) in duplicates. For the phenol-based extraction (Trizol), $60 \mu \mathrm{l}$ chloroform-isoamylalcohol was added to $300 \mu \mathrm{l}$ Trizol RNA extraction solution. After mixing, the phases were separated by centrifugation (10000 rpm, $10 \mathrm{~min}, \mathrm{RT})$. The aqueous phase was transferred to a new tube and $2 \mu \mathrm{l}$ co-precipitant (PelletPaint, Novagen, San Diego, CA, USA) and $160 \mu \mathrm{l}$ isopropanol (1 volume) was added. After mixing and incubation for $5 \mathrm{~min}$ at RT, RNA was precipitated by centrifugation (13 $000 \mathrm{rpm}$, $10 \mathrm{~min}, \mathrm{RT}$ ). The precipitant was washed twice with $70 \%$ ethanol. After removal of the ethanol and 15 min drying, the RNA was resolved in $20 \mu \mathrm{l}$ RNAse-free water (Ambion). In the case of columnbased extraction, total RNA was extracted using the MicroRNA isolation kit (Qiagen) according to the manufacturer's instructions. Membrane bound RNA was eluted from the column in a volume of $20 \mu \mathrm{l}$. To all RNA samples, $1 \mu \mathrm{l}$ RNAsin (Promega UK, Southampton, UK) was added and the samples were stored at $-80^{\circ} \mathrm{C}$. The total amount of RNA isolated from tonsil and colon tissue samples ranged from 0.4 to $5.1 \mu \mathrm{g}$.

\section{Microchip Gel Electrophoresis}

The Agilent 2100 Bioanalyzer and RNA 6000 Pico Labchip kit (Agilent Biotechnologies, Palo Alto, CA, USA) were utilized to evaluate the RNA quality of the tissue samples. The RNA sample was diluted and $1 \mu \mathrm{l}$, corresponding to approximately $1.5 \%(\mathrm{v} / \mathrm{v})$ of each RNA probe, was transferred to the PicoLabchip, together with $1 \mu$ l of RNA 6000 ladder (Ambion). The analysis was performed according to the manufacturers' instructions and the results are shown as electropherograms.

\section{cDNA Synthesis and Quantitative Real-Time PCR}

cDNA was transcribed from $25 \%(5 \mu \mathrm{l}, \mathrm{v} / \mathrm{v})$ of each RNA probe. To $5 \mu \mathrm{l}(1 \mu \mathrm{g} / \mu \mathrm{l})$ RNA solution, $1 \mu \mathrm{l}$ oligodT primers (dT17) and $1 \mu \mathrm{l} 10 \mathrm{nM}$ dNTPmix (Clontech, Palo Alto, CA, USA) was added. After heating 
for $10 \mathrm{~min}$ at $65^{\circ} \mathrm{C}$ and immediate chilling on ice, reverse transcription was performed at $42^{\circ} \mathrm{C}$ for $1 \mathrm{~h}$ after adding $4 \mu \mathrm{l}$ first strand buffer, $2 \mu \mathrm{l}$ DTT, $1 \mu \mathrm{l}$ RNAsin (Promega) and $1 \mu \mathrm{l}$ Superscript II reverse transcriptase (Invitrogen). The reaction was stopped at $65^{\circ} \mathrm{C}$ for $20 \mathrm{~min}$ and the RNA was digested with $1 \mu \mathrm{l}$ RNAseH (Clontech) for $30 \mathrm{~min}$ at $37^{\circ} \mathrm{C}$. Then, $2 \mu \mathrm{l}$ of the cDNA solution $(10 \%)$ was used for a 40-cycle Sybrgreen PCR assay using the Sybrgreen Universal PCR Master Mix (Applied Biosystems, Foster City, CA, USA) with the primers described in Table 1. The reaction was performed with the ABI PRISM 7000HT real-time PCR cycler (Applied Biosystems) under conditions recommended by the manufacturer. Expression levels were normalized to expression of the housekeeping gene glyceraldehyde-3-phosphate dehydrogenase (GAPDH). The normalized expression levels of the genes (cfos, TGF $\beta 1$, SMAD7, HIF1 $\alpha$, Bcl2 and PCNA, respectively) were compared to the expression level at time point $0 \mathrm{~h}$ (set to 1.0 for relative comparison).

\section{Results}

\section{RNA Integrity in Tonsil Tissue: Effect of Storage Duration and Media}

In order to evaluate the influence of transport media and storage time under controlled conditions, fresh tonsil tissue was used as detailed in Figure 1. The

Table 1 Primer sequences and concentrations used for real-time PCR

\begin{tabular}{lll}
\hline Primer & Forward & Backward \\
\hline GAPDH $(200 \mathrm{nM})$ & CCCATGTTCGTCATGGGTGT & TGGTCATGAGTCCTCCACGATA \\
cfos $(200 \mathrm{nM})$ & CGAGCCCTTTGATGACTTCCT & GGAGCGGGCTGTCTCAGA \\
TGF $\beta 1(100 \mathrm{nM})$ & GTGACAGCAGGGATAACACACTG & CATGAATGGTGGCCAGGTC \\
SMAD7 $(100 \mathrm{nM})$ & AGAGGCTGTGTTGCTGTGAATC & GCAGAGTCGGCTAAGGTGATG \\
HIF1 $\alpha^{\mathrm{a}}(200 \mathrm{nM})$ & CGTTCCTTCGATCAGTTGTC & TCAGTGGTGGCAGTGGTAGT \\
PCNA $(200 \mathrm{nM})$ & GCGCTAGTATTTGAAGCACCAA & CGATCTTGGGAGCCAAGTAGTA \\
Bcl2 $^{\mathrm{a}}(200 \mathrm{nM})$ & TCCGCATCAGGAAGGCTAGA & AGGACCAGGCCTCCAAGCT
\end{tabular}

${ }^{\mathrm{a}}$ Primer sequences were obtained from public RTPrimerDB database ${ }^{24}$ (http://medgen.UGent.be/rtprimerdb/).

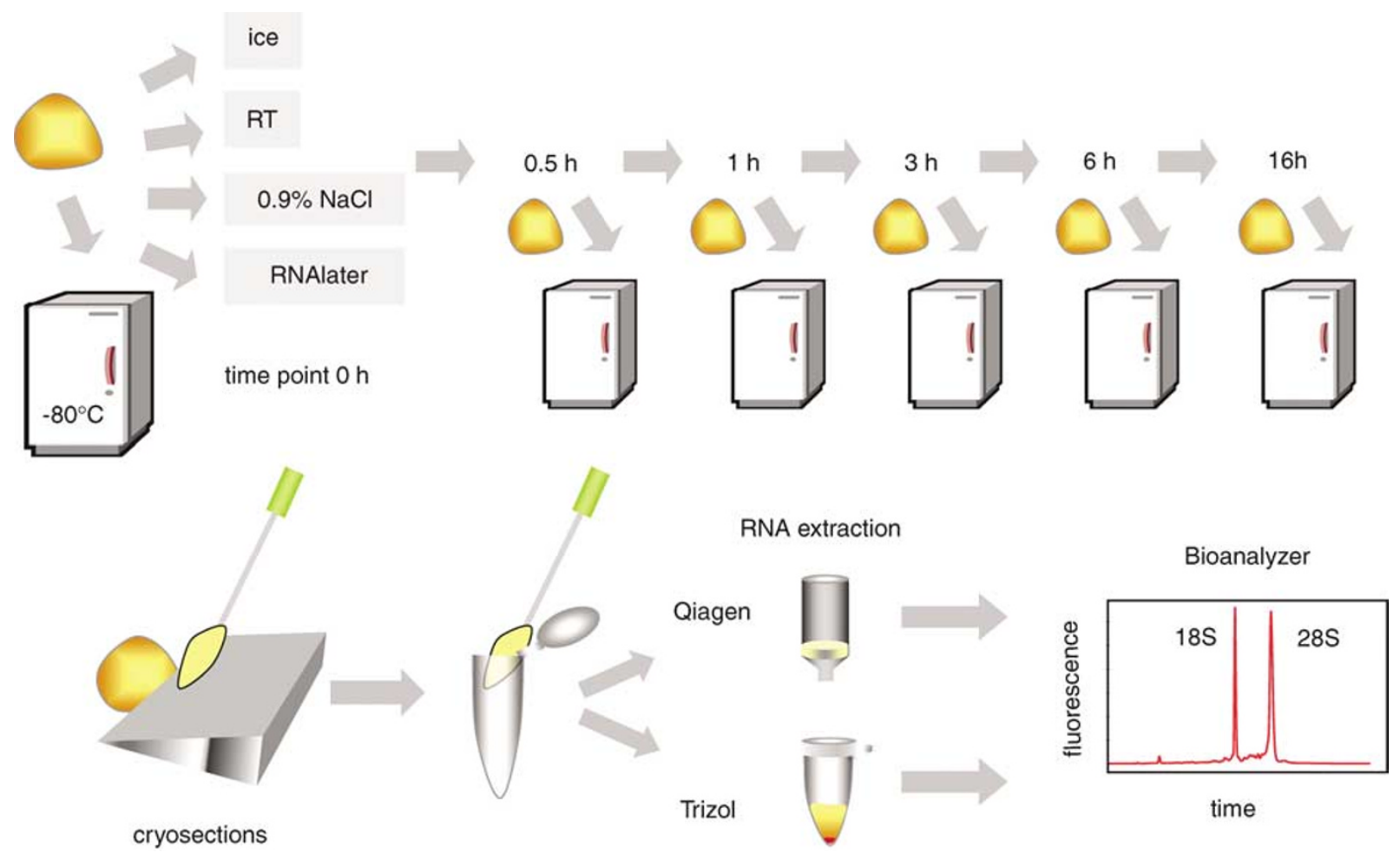

Figure 1 Experimental design. Fresh surgical specimens of tonsil and colon tissue were cut in equal pieces of approximately $5 \times 5 \times 5 \mathrm{~mm}$. As references, some samples were frozen directly after surgery (time point $0 \mathrm{~h}$ ). The other portions were stored at room temperature (RT), on ice, or immersed in normal saline (only tonsil tissue) or RNAlater. After 0.5, 1, 3, 6 and $16 \mathrm{~h}$, tissue fractions were removed, snap frozen and stored at $-80^{\circ} \mathrm{C}$ until further processing. To extract the RNA, the samples were cut in a cryostat and sections were transferred to RNA extraction buffer (Trizol or Qiagen extraction buffer). After RNA purification, the amount and quality of RNA was analysed using microchip gel electrophoresis (Bioanalyzer). Distinct 18S and 28S ribosomal RNA peaks indicate intact RNA. 
time point $\mathrm{Oh}$

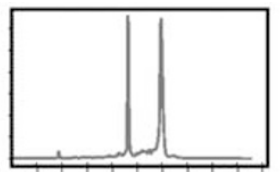

room temperature

$0.5 \mathrm{~h}$
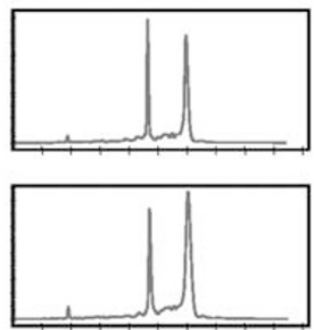

$3 \mathrm{~h}$

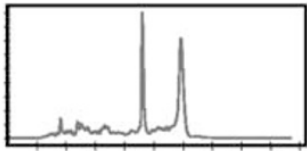

$6 \mathrm{~h}$

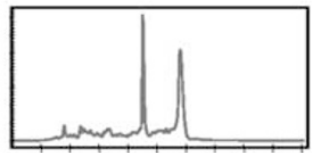

$16 \mathrm{~h}$

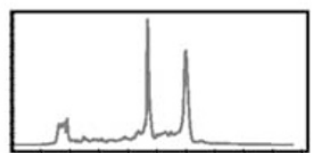

ice
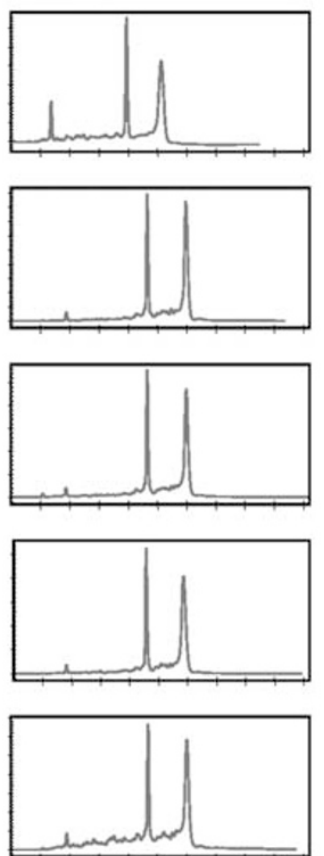

$0.9 \% \mathrm{NaCl}$
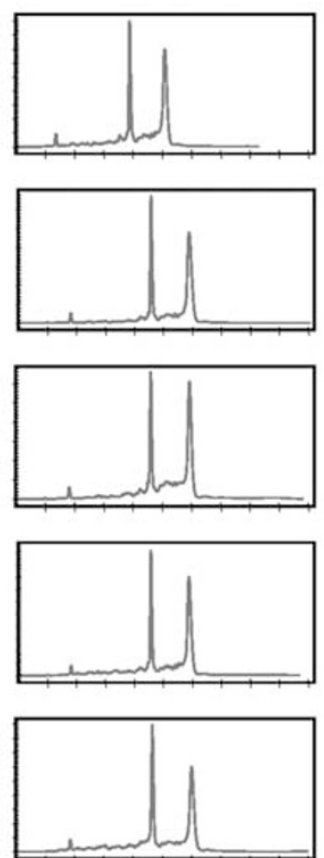

RNAlater
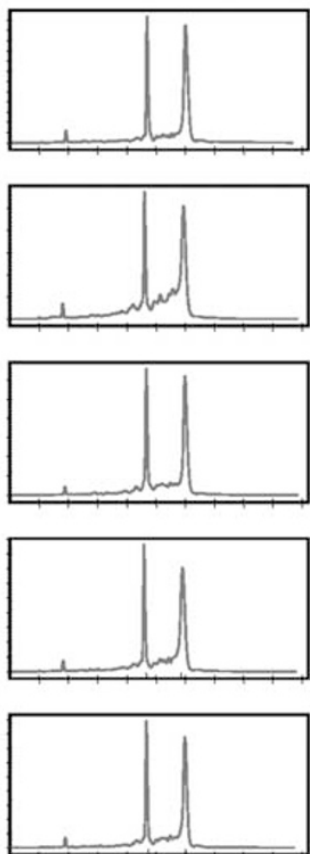

Figure 2 RNA integrity of tonsil tissue under different transport conditions. Purified RNA was analysed using microchip gel electrophoresis (Bioanalyzer) and the results are presented as electropherograms. The RNA of all samples (stored at room temperature (RT), on ice, in normal saline or RNAlater) at all time points $(0,0.5,1,3,6$ and $16 \mathrm{~h})$ showed distinct ribosomal peaks indicating no significant degradation. Representative RNA samples purified with a Qiagen column are shown.

RNA quality was assessed on the basis of the electropherograms after microchip gel electrophoresis and quantified by calculating the ratios of the ribosomal subunits $28 \mathrm{~S}$ and $18 \mathrm{~S}$. The electropherograms of all samples showed distinct ribosomal peaks (Figure 2), indicating well-preserved RNA. No signs of degradation were detected during storage on ice or in RNAlater, even after incubation for $16 \mathrm{~h}$. Slight signs of degradation were observed only after long storage ( 6 and $16 \mathrm{~h}$ ) at room temperature or in saline. When the RNA integrity was quantified by using $28 \mathrm{~S} / 18 \mathrm{~S}$ ribosomal ratios, a tendency towards lower ratios was observed for all conditions compared to time point $0 \mathrm{~h}$ (Figure 3). However, a significant decrease was only observed for storage in saline between time points 0 and $16 \mathrm{~h}(28 \mathrm{~S} / 18 \mathrm{~S}$ ratio: $1.55 \pm 0.19$ at $0 \mathrm{~h}$ vs $1.24 \pm 0.07$ at $16 \mathrm{~h}$, $P=0.01)$. All other comparisons showed no relevant differences ( $P>0.14$, all comparisons).

\section{Morphology of Tonsil Tissue in the Experimental Set-Up}

Morphological examination of frozen sections showed intact tonsil architecture in all samples

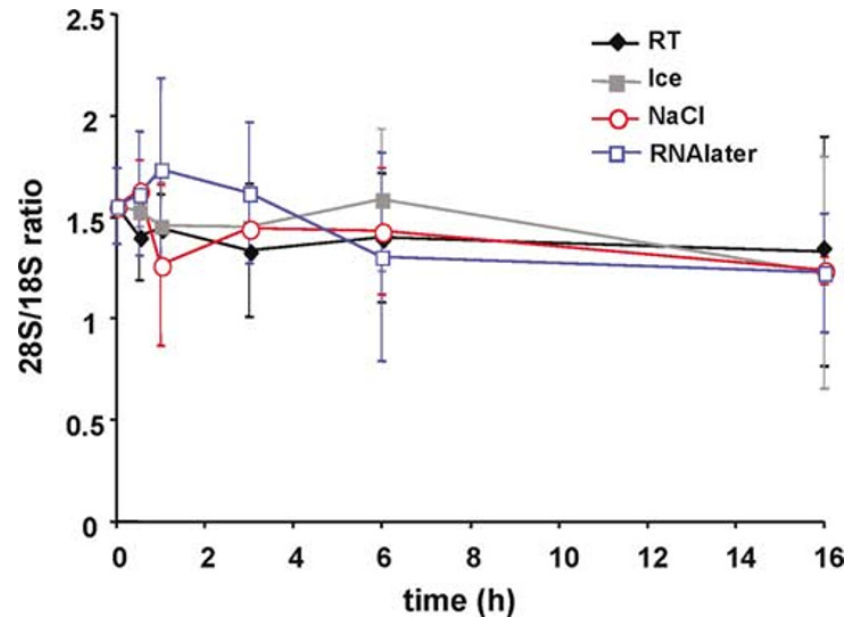

Figure 3 RNA integrity over time. In the tonsil samples, the ratios of the ribosomal peaks $(28 \mathrm{~S} / 18 \mathrm{~S})$ were calculated based on the electropherograms. RNA was extracted from four samples (two samples with Trizol and two with the Qiagen-Kit). Values represent the mean and standard deviation of these four analyses.

(Figure 4). No signs of cellular decomposition could be detected in the lymphoid cells or in the squamous crypt epithelium. Tonsil tissue kept in 
206
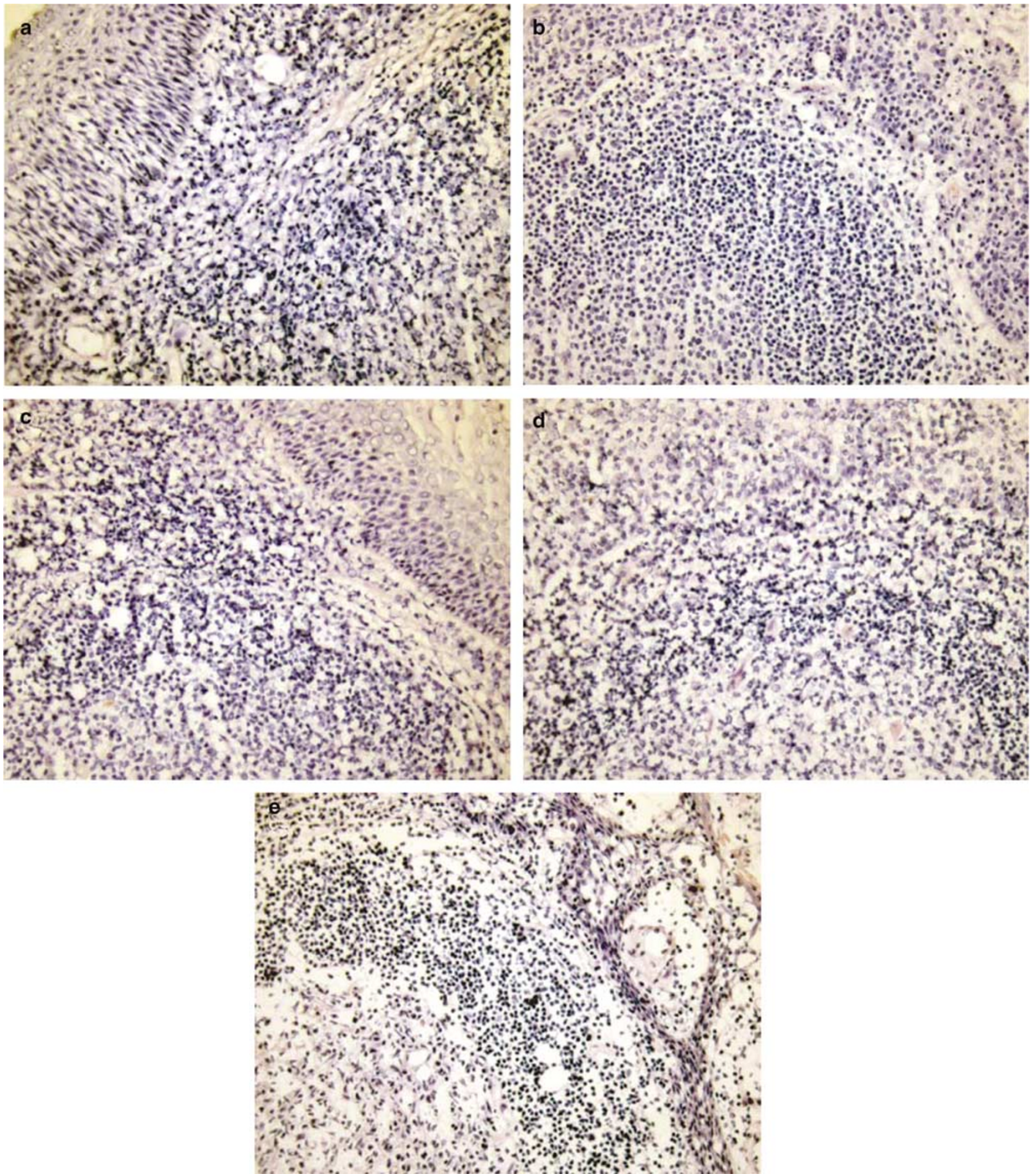

Figure 4 Morphology of tonsil tissue under different transport conditions. Frozen tonsil specimens were cut in sections (4 $\mu \mathrm{m})$ by the tape transfer technique and stained with hematoxylin-eosin. The panels show the histology of a reference sample that was frozen immediately after surgery (a) and sections from samples stored for $16 \mathrm{~h}$ at room temperature (b), on ice (c), in normal saline (d) and in RNAlater (e). Original magnification $\times 10$.

RNAlater developed a firmer consistency and was difficult to section. Microscopically, these samples exhibited signs of tissue condensation, cell shrinkage and hyperchromatic nuclei.

\section{RNA Integrity in Colon Tissue}

We also wanted to test the influence of storage time and media on the RNA integrity in another tissue 
type. Therefore, fresh normal colon tissue was utilised in an experimental set-up similar to that of the tonsil tissue. The results are summarized in Figure 5. Again the electropherograms showed distinct ribosomal peaks even after long storage on ice, at room temperature, and in RNAlater. Morphological examination of frozen sections revealed that all samples were representative and contained mucosa, submucosa and a variable amount of muscular layer. Colon histology was well preserved in all samples. However, after RNAlater incubation, similar tissue shrinkage phenomena were visible as in the tonsil experiment (data not shown).

\section{RNA Integrity of Tissue Samples Stored Routinely within the Biobank}

In order to assess the RNA quality in tissue samples stored routinely in our frozen tissue biobank, 47 samples were chosen representing a wide range of different surgical specimens. From many specimens, both normal and malignant components were analysed separately. In 45 out of 47 (96\%) samples, clear ribosomal peaks were visible in the electropherograms obtained from the Bioanalyzer. The 28S/ $18 \mathrm{~S}$ ratios are shown in Figure 6. No pattern of higher susceptibility to RNA degradation could be

time point $\mathrm{Oh}$

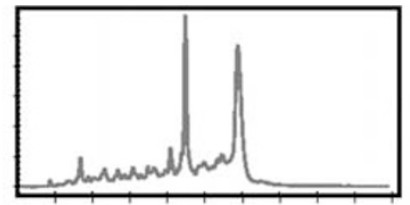

room temperature

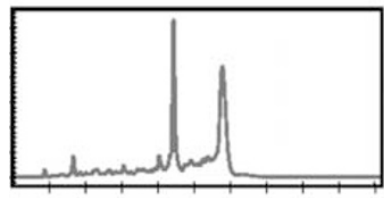

$0.5 \mathrm{~h}$

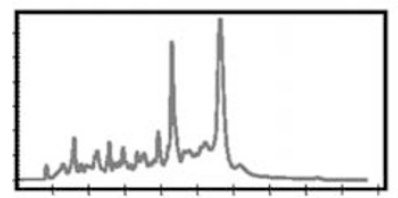

$1.0 \mathrm{~h}$

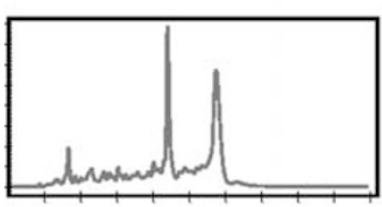

$\mathbf{3 h}$

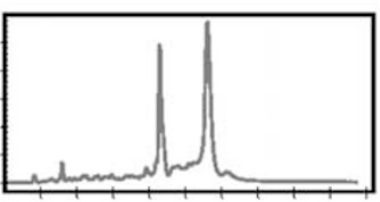

$6 \mathrm{~h}$

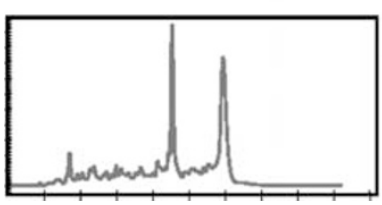

ice
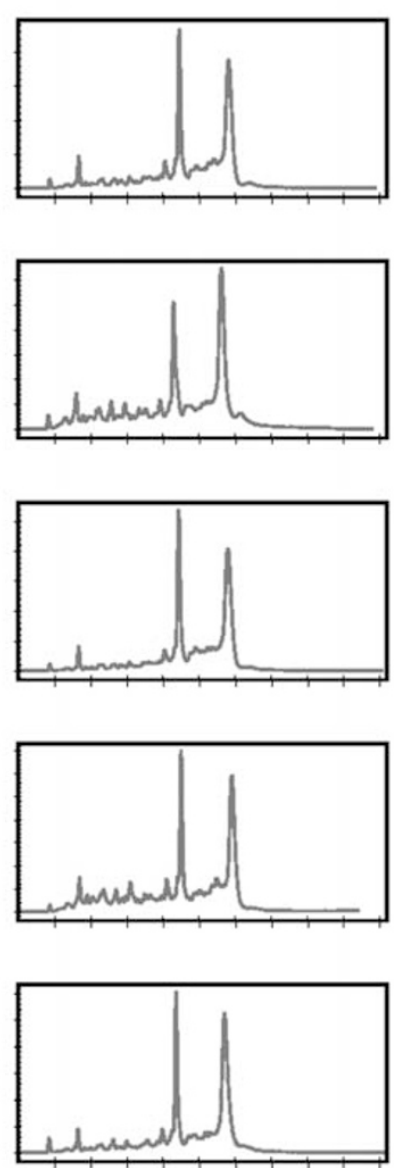

RNAlater
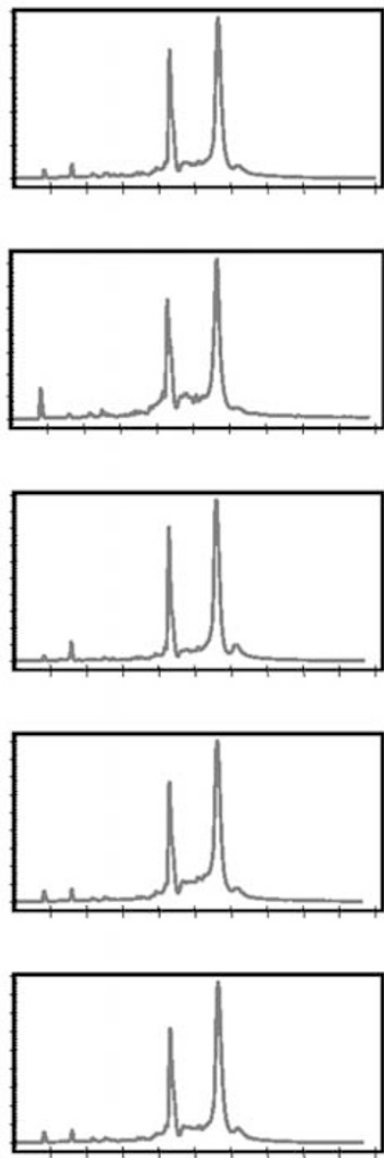

Figure 5 RNA integrity of colon tissue under different transport conditions. Normal colon tissue was processed as outlined in Figure 1. Sample storage in saline was omitted in this experiment due to lack of available tissue. Purified RNA was analysed using microchip gel electrophoresis (Bioanalyzer) and the results are presented as electropherograms. The RNA of all samples (stored at RT, on ice or in RNAlater) and at all time points $(0,0.5,1,3,6,16 \mathrm{~h})$ showed distinct ribosomal peaks indicating no significant degradation. Representative RNA samples purified with a Qiagen column are shown. 


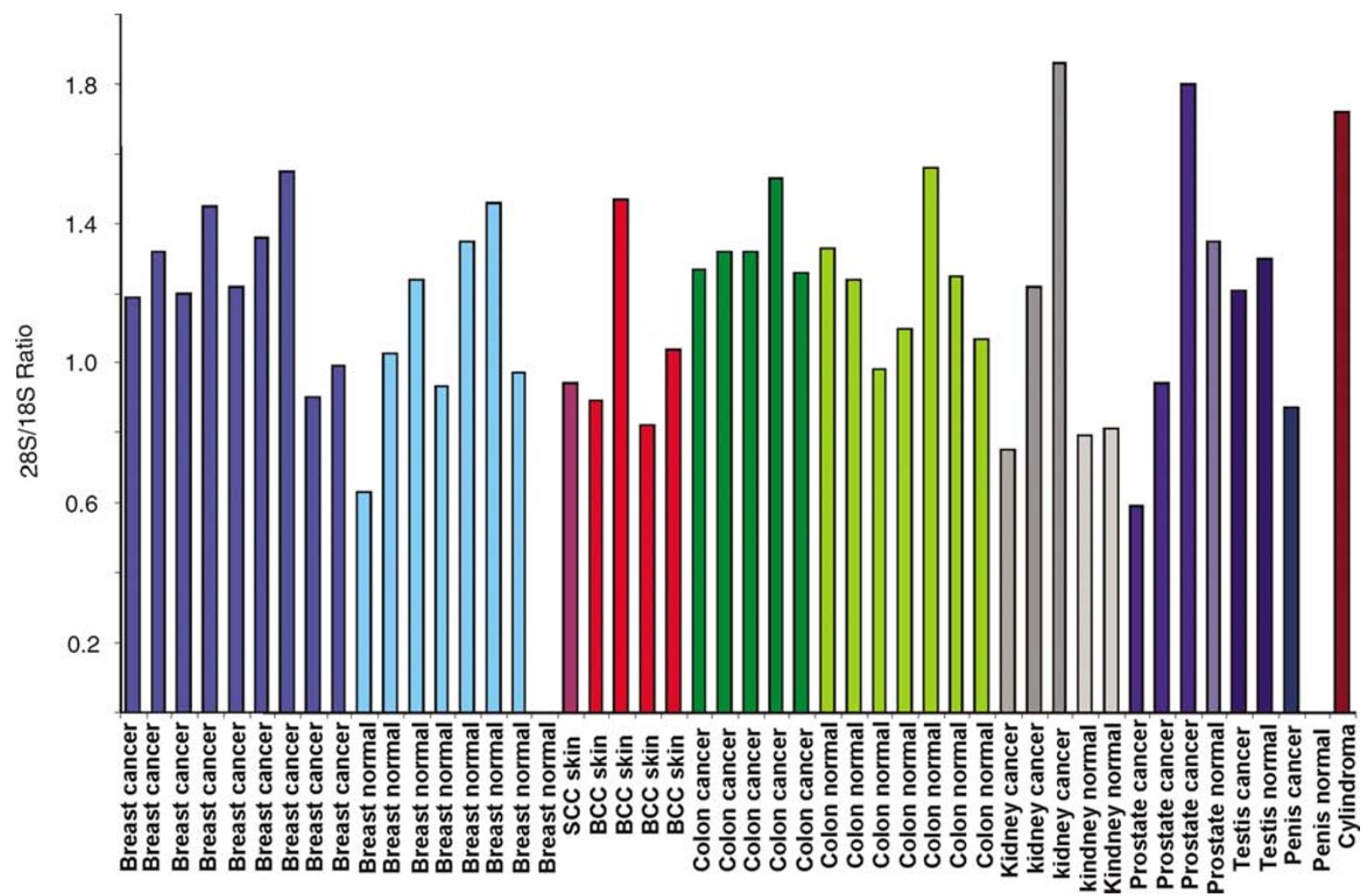

Figure 6 RNA was purified from a number of different tissues of the local frozen tissue biobank (Department of Pathology, Uppsala University Hospital). Tissue type as indicated below each bar (SCC = squamous cell carcinoma, BCC=basal cell carcinoma). The RNA was extracted using Trizol and analysed with a Bioanalyzer. The ratios of both ribosomal peaks (28S/18S) were calculated based on the electropherograms. Only two samples failed to show ribosomal RNA peaks.

detected with respect to a specific tissue type, nor was there any obvious difference between benign and malignant samples. For 22 specimens, the exact transportation times on ice were available. When the $28 \mathrm{~S} / 18 \mathrm{~S}$ ratios of samples with longer transport times $(>1 \mathrm{~h})$ were compared to samples with shorter transportation times $(<1 \mathrm{~h})$, no relevant difference regarding RNA integrity could be detected (28S/18S ratio $<1$ h: $1.16 \pm 0.37$ vs $>1$ h: $1.09 \pm 0.36, P=0.67$ ). In general, the RNA content was higher in cancer tissue compared to normal tissue counterparts (eg $1.95 \pm 0.8 \mu \mathrm{g}$ breast cancer vs $0.54 \pm 0.8 \mu \mathrm{g}$ normal breast), likely reflecting higher cellularity in the cancer samples.

\section{Gene Expression Levels: Effect of Storage Duration and Transport Media}

To investigate if storage conditions and storage time induced changes of gene expression, six genes were analysed in the tonsil tissue experimental set-up described above (Figure 7). The genes were selected to represent markers of different cellular regulatory pathways; cfos (immediate early response gene), TGF $\beta 1$ (growth factor), SMAD7 (signal transduction molecule), HIF1 $\alpha$ (hypoxia response), Bcl2 (apopto- sis regulator), PCNA (cell cycle). The analysed marker genes remained basically stable when the tissue was kept on ice. Only after $16 \mathrm{~h}$, a slight downregulation of HIF $1 \alpha$, TGF $\beta 1$ and bcl 2 was noted. At room temperature, the expression levels of cfos revealed a dramatic downregulation after $6 \mathrm{~h}$. In contrast, SMAD7, TGF $\beta 1$ and PCNA expression levels remained quite stable. Incubation in normal saline resulted in a relevant upregulation of cfos and SMAD7 after $30 \mathrm{~min}$ and there was marked upregulation of HIF $1 \alpha$, bcl-2 and PCNA at $16 \mathrm{~h}$. The most significant changes in gene expression patterns were observed after incubation in RNAlater. The expression levels of cfos, TGF $\beta 1$, Bcl2 and SMAD7 increased significantly after $0.5-6 \mathrm{~h}$. Also in RNAlater, the gene expression levels showed the highest degree of variation within the replicates.

\section{Discussion}

Storage of tissues with intact morphology, proteins, DNA and RNA for use in research and diagnostics, is the ultimate objective of a biobank. Avoiding RNA degradation is a major challenge in this process. The aim of the present study was to test different transport conditions for fresh tissue specimens in 

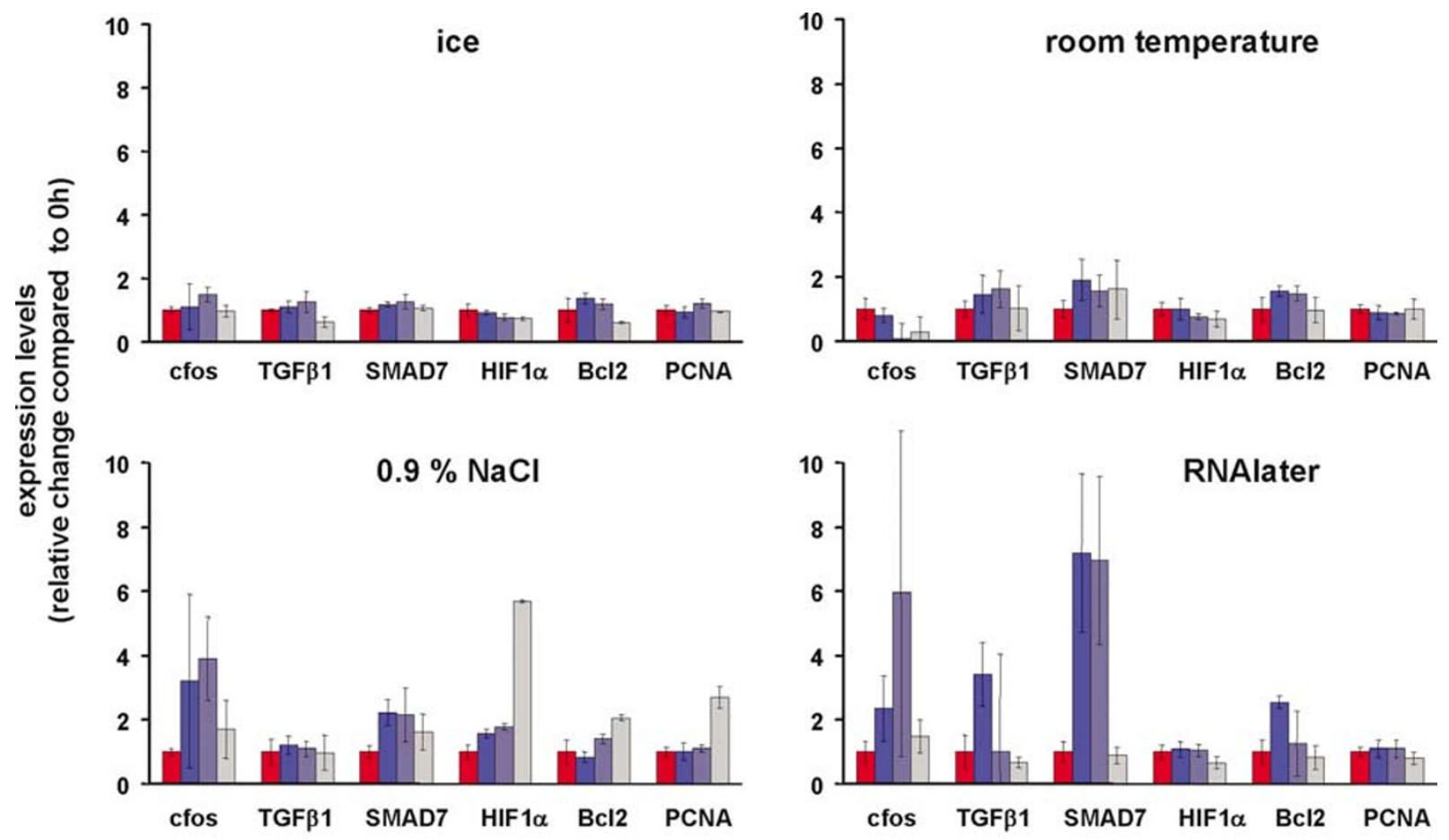

Oh

$0.5 \mathrm{~h}$

$6 \mathrm{~h}$

$16 \mathrm{~h}$

Figure 7 Gene expression levels under different storage conditions. RNA isolated from the tonsil tissue experiment was transcribed to cDNA and analysed using primers for cfos, TGF $\beta 1$, SMAD7, HIF1 $\alpha$, Bcl2 and PCNA. The results were normalised to GAPDH expression. Relative gene expression at three different time points $(0.5,6$ and $16 \mathrm{~h})$ was compared to time point $0 \mathrm{~h}$ (set to 1.0$)$. The results are shown as mean and standard deviation.

order to preserve good RNA quality. An experimental set-up was designed to reflect commonly used strategies for handling nonfixed frozen tissues. Four different conditions were tested: (1) Direct placing of surgical specimens on ice until further processing at the pathology department represents a standard practice at many institutions, including ours. The time lag before a piece of tissue is frozen can be several hours if the tissue specimen is referred from a smaller hospital to a main centre. (2) RNAlater represents a commercially available fixative particularly recommended to preserve RNA and is used in several well-organised tissue biobank projects. ${ }^{11,12,14}$ (3) A recent study showed that isotonic saline $(0.9 \% \mathrm{NaCl})$ provides an alternative to stabilise RNA in tissue samples even at temperatures up to $37^{\circ} \mathrm{C}^{8}$ and was therefore included in the study. (4) Since the time after surgical excision ex vivo at room temperature might vary, a time course experiment at room temperature was also performed. The results showed that RNA is stable for several hours in nonfixed tonsil tissue processed according to the four different storage strategies described above. Even after overnight storage (16 h) at room temperature, RNA was not significantly degraded. The same storage conditions, except immersion in saline, were also tested on fresh colon tissue. Again RNA appeared to be stable during hours of storage in a nonfixed state at room temperature, on ice and in RNAlater. In addition, we examined a large number of frozen tissue samples assembled during routine diagnostic pathology. Independent of tissue type, more than $95 \%$ of the samples exhibited clear ribosomal RNA peaks indicating no major degradation. Neither was there any obvious difference in RNA integrity between benign and malignant tissue. Taken together, the results provide strong evidence that stable RNA is a general phenomenon in intact fresh tissue. We believe that RNA degradation detected in some of our biobank samples more likely is explained by surgical trauma before transport, or by suboptimal storage or mistreatment after biobanking, rather than by a long transport time on ice as a nonfixed surgical specimen.

RNA is considered a most fragile molecule. The ubiquitous presence of RNAses requires efforts to avoid RNAse contamination during laboratory work. Also, inhibition of endogenous RNAse activity might be necessary. Purified RNA is susceptible to rapid degradation and must be handled with extreme care. ${ }^{12,19}$ However, one should take into consideration that extracted RNA in a test tube and cellular RNA in the cytosolic ambience of an intact cell represent two different settings for a potential degradation process. Histological examination of the 
samples in this study indicates intact cellular and architectural integrity in fresh tissues for many hours. We thus believe that the stability of RNA in fresh tissue is due to preserved cellular structure. In agreement with our observations, studies have been published that show intact RNA in tissue after incubation at room temperature over longer periods of time. ${ }^{15,20-22}$ However, these findings were only shown for specific tissue types and under certain specific experimental conditions.

Even if RNA as molecules are preserved it is possible that gene expression is changed during transport of nonfixed tissues. This could result from surgical trauma, hypoxia, influence of fixation chemicals during diffusion into the tissue and other types of cellular stress. Therefore, six genes were selected that are regulated in response to different stimuli. The expression of cfos, known to be highly sensitive to cellular stress, showed the highest degree of regulation. Other genes (TGF $\beta 1$, HIF $1 \alpha$, SMAD7 and Bcl2) also revealed relevant changes of expression under certain storage conditions. However, during storage on ice, the expression levels of the six genes remained quite stable over a longer period of time. Immersion in RNAlater resulted in the largest variability in gene expression levels, both comparing different time points as well as in the deviation among replicates. This is in contrast to other studies certifying RNAlater as an reliable agent not only to stabilise RNA but also to maintain expression profiles. ${ }^{11,12,23}$ However, none of these studies included a direct comparison of the expression of single genes between the tested conditions. To our knowledge, there is only one study comparing storage time dependency of gene expression levels using quantitative real-time PCR. ${ }^{20}$ Fractions of breast cancer tissue were kept at room temperature for up to $3 \mathrm{~h}$ and gene expression of four housekeeping genes was analysed. Real-time PCR revealed stable expression levels over time. However, highly regulated genes like cfos were not included in this study.

In conclusion, our analyses indicate that RNA is quite stable during storage of nonfixed surgical specimens. The data does not support the use of RNA-stabilizing agents during routine transport of fresh specimens from surgery to biobank facilities since no obvious advantageous effects were detected. These findings might facilitate the logistics regarding transport of fresh tissues in biobank projects and suggest that the common procedure to transfer fresh surgical specimens on ice represents a reliable procedure to preserve RNA quality and gene expression profiles.

\section{Acknowledgements}

The Fresh Tissue Biobank at the Department of Pathology, Uppsala University Hospital, is supported by the National Biobank Program funded by
Wallenberg Consortium North and Swegene. We thank Dr Pia Rehfisch for critical reading of the manuscript. The skilful technical assistance of Natalia Mochalina is gratefully acknowledged. The study was in parts supported by the Dr Mildred Scheel Cancer Foundation (Germany) and by a Grant-in-Aid for Scientific Research from the Japan Society for the promotion of Science (\#15592004).

\section{References}

1 Marx J. Medicine. DNA arrays reveal cancer in its many forms. Science 2000;289:1670-1672.

2 Fassunke J, Majores M, Ullmann C, et al. In situ-RT and immunolaser microdissection for mRNA analysis of individual cells isolated from epilepsy-associated glioneuronal tumors. Lab Invest 2004;84:1520-1525.

3 Micke P, Bjornsen T, Scheidl S, et al. A fluid cover medium provides superior morphology and preserves RNA integrity in tissue sections for laser microdissection and pressure catapulting. J Pathol 2004;202:130-138.

4 Bullinger L, Dohner K, Bair E, et al. Use of geneexpression profiling to identify prognostic subclasses in adult acute myeloid leukemia. $N$ Engl J Med 2004;350:1605-1616.

5 Hauser P, Schwarz C, Mitterbauer C, et al. Genomewide gene-expression patterns of donor kidney biopsies distinguish primary allograft function. Lab Invest 2004;84:353-361.

6 van de Vijver MJ, He YD, van't Veer LJ, et al. A geneexpression signature as a predictor of survival in breast cancer. N Engl J Med 2002;347:1999-2009.

7 van 't Veer LJ, Dai H, van de Vijver MJ, et al. Gene expression profiling predicts clinical outcome of breast cancer. Nature 2002;415:530-536.

8 Vincek V, Nassiri M, Knowles J, et al. Preservation of tissue RNA in normal saline. Lab Invest 2003;83: 137-138.

9 Vincek V, Nassiri M, Nadji M, et al. A tissue fixative that protects macromolecules (DNA, RNA, and protein) and histomorphology in clinical samples. Lab Invest 2003;83:1427-1435.

10 Wester K, Asplund A, Backvall H, et al. Zinc-based fixative improves preservation of genomic DNA and proteins in histoprocessing of human tissues. Lab Invest 2003;83:889-899.

11 Ellis M, Davis N, Coop A, et al. Development and validation of a method for using breast core needle biopsies for gene expression microarray analyses. Clin Cancer Res 2002;8:1155-1166.

12 Florell SR, Coffin CM, Holden JA, et al. Preservation of RNA for functional genomic studies: a multidisciplinary tumor bank protocol. Mod Pathol 2001;14:116-128.

13 Gillespie JW, Best CJ, Bichsel VE, et al. Emmert-Buck MR evaluation of non-formalin tissue fixation for molecular profiling studies. Am J Pathol 2002;160: 449-457.

14 Guo D, Catchpoole DR. Isolation of intact RNA following cryosection of archived frozen tissue. Biotechniques 2003;34:48-50.

15 Breit S, Nees M, Schaefer U, et al. Impact of preanalytical handling on bone marrow mRNA gene expression. Br J Haematol 2004;126:231-243.

16 Hengstler JG, Pilch H, Schmidt M, et al. Metallothionein expression in ovarian cancer in relation to 
histopathological parameters and molecular markers of prognosis. Int J Cancer 2001;95:121-127.

17 Srinivasan M, Sedmak D, Jewell S. Effect of fixatives and tissue processing on the content and integrity of nucleic acids. Am J Pathol 2002;161:1961-1971.

18 Riddick AC, Barker C, Sheriffs I, et al. Banking of freshfrozen prostate tissue: methods, validation and use. BJU Int 2003;91:315-323; discussion 323-324.

19 Sambrook J, Fritsch EF, Maniatis T (eds). Extraction and purification of RNA. In: Molecular Cloning-a Laboratory Manual, 2nd edn. Cold Spring Harbor Laboratory Press: New York, 1989.

20 Ohashi Y, Creek KE, Pirisi L, et al. RNA degradation in human breast tissue after surgical removal: a timecourse study. Exp Mol Pathol 2004;77:98-103.
21 Almeida A, Paul Thiery J, Magdelenat H, et al. Gene expression analysis by real-time reverse transcription polymerase chain reaction: influence of tissue handling. Anal Biochem 2004;328:101-108.

22 Jewell SD, Srinivasan M, McCart LM, et al. Analysis of the molecular quality of human tissues: an experience from the Cooperative Human Tissue Network. Am J Clin Pathol 2002;118:733-741.

23 Mutter GL, Zahrieh D, Liu C, et al. Comparison of frozen and RNALater solid tissue storage methods for use in RNA expression microarrays. BMC Genomics 2004;5:88.

24 Pattyn F, Speleman F, De Paepe A, et al. RTPrimerDB: the real-time PCR primer and probe database. Nucleic Acids Res 2003;31:122-123. 